\title{
A COMPARISON OF METHODS OF MEASURING THE DIFFUSING \\ CAPACITY OF THE LUNGS FOR CARBON MONOXIDE. INVESTIGATION BY FRACTIONAL ANALYSIS OF THE ALVEOLAR AIR
}

\author{
By R. MARSHALL 1
}

(From the Medical Unit, St. Bartholomew's Hospital, London, England)

(Submitted for publication August 16, 1957; accepted November 7, 1957)

The diffusing capacity of the lungs for carbon monoxide is measured as the ml. of carbon monoxide $(\mathrm{CO})$ that can be transferred from the alveoli to the blood per $\mathrm{mm}$. $\mathrm{Hg}$ pressure difference of $\mathrm{CO}$ between the alveoli and the blood. This measurement can be made by steady state techniques or by the single breath method. Two steady state methods have been described recently, which differ in the methods by which the mean alveolar $\mathrm{CO}$ concentration is measured. In one method (1) the mean alveolar CO concentration is calculated by assuming that $\mathrm{CO}$ and $\mathrm{CO}_{2}$ have the same dead space and that the partial pressure of $\mathrm{CO}_{2}$ in the arterial blood is equal to the mean alveolar partial pressure of $\mathrm{CO}_{2}$. This method requires an arterial puncture and accurate estimation of the partial pressure of $\mathrm{CO}_{2}$ in the arterial blood so that its routine and repeated use in patients is limited. The other steady state method described by Bates, Boucot, and Dormer (2) uses the end tidal $\mathrm{CO}$ as a measure of the mean alveolar $\mathrm{CO}$ and, as it is a bloodless method, can more easily be used for repeated measurements on patients. These two methods give results which lie in a similar range although some of the values for normal subjects reported by Bates and Pearce (3) are low in relation to the usually accepted range. The single breath method of Krogh and Krogh (4), recently modified by Ogilvie, Forster, Blakemore, and Morton (5), is simple to carry out but comparison with the steady state method of Filley has shown (6) that the single breath method gives higher values in normal subjects; in disease the values obtained by the single breath method may be very much higher than those obtained by the steady state method. Similar re-

1 Cooper and Coventson Research Scholar, St. Bartholomew's Hospital. Present Address: The Nuffield Department of Surgery, The Radcliffe Infirmary, Oxford, England. sults have been obtained in this laboratory when comparing the single breath method with the steady state method of Bates and co-workers (2). By this latter method patients with emphysema give a uniformly low $\mathrm{D}_{\mathrm{L}}{ }^{2}$ but many of these patients have a normal $D_{\mathbf{L}}$ measured by the single breath method. Because of these findings it was decided to make further comparisons of the single breath and steady state methods of measuring $D_{L}$ by applying methods for fractional analysis of the alveolar air.

\section{METHODS}

The single breath measurements of $D_{L}$. These were made using the apparatus and methods described by Ogilvie and co-workers (5). The gas mixture inspired consisted of 14 per cent helium, 0.125 per cent $\mathrm{CO}, 20$ per cent $\mathrm{O}_{2}$ and the remainder $\mathrm{N}_{2}$. Before and after each determination on the normal subjects the alveolar air was equilibrated with the carboxyhemoglobin in the blood by breath holding for the maximum time at the functional residual capacity (F.R.C.) The patients equilibrated the blood and alveolar $\mathrm{CO}$ by rebreathing the expired air for 30 to 45 seconds (7). These two methods have been found to give the same result and the patients find rebreathing easier to do than breath holding. The back pressure of carbon monoxide before breath holding was calculated by correcting the equilibrated $\mathrm{CO}$ according to the following equation:

Back pressure of $\mathrm{CO}$ in lungs during breath holding

$$
=\text { equilibrated } \mathrm{CO} \text { per cent } \times \frac{\text { B.H. } \mathrm{O}_{2}}{\text { equil. } \mathrm{O}_{2}},
$$

where B.H. $\mathrm{O}_{2}$ is the tension of $\mathrm{O}_{2}$ in the lungs during the test, and equil. $\mathrm{O}_{2}$ is the tension of $\mathrm{O}_{2}$ in the rebreathing bag at the end of the equilibration. This correction is only approximate since it assumes that the hemoglobin in the capillaries is fully saturated with oxygen, but in these subjects the equilibration $\mathrm{CO}$ tension was small (approximately 0.1 to 0.5 per cent of the tension of $\mathrm{CO}$ in the alveoli during breath holding) and the error introduced is small. This back pressure of $\mathrm{CO}$ was sub-

2 The abbreviation $D_{L}$ is used to designate the apparent diffusing capacity of the lung for $\mathrm{CO}$ (5). 
tracted from the expired $\mathrm{CO}$ per cent for calculation of $D_{\mathrm{L}}$ (5).

Measurements of the single breath $D_{L}$ in normal subjects were made at full inspiration and at a volume approximating the F.R.C. Two measurements were made at each of the volumes. Measurements were made at full inspiration only in the patients with emphysema because of the small volume of expired air available for analysis and because, in these patients, the inspiratory capacity is small in relation to the F.R.C. The predicted normal values for $D_{L}$ were calculated from the regression equation of Ogilvie and co-workers (5).

Single breath measurements of $D_{L}$ with fractional analysis of the expired air. The apparatus used for the fractional analysis of the expired air is shown in Figure 1. It was essentially the same as that described by Ogilvie except that no three-way tap was inserted between the valve box and the mouthpiece, and distal to the expiratory valve a three-way tap $\left(T_{2}\right)$ and a 4.5 meter length of rubber tubing of $2.5 \mathrm{~cm}$. bore (C) connected the expiratory valve to the aspirator bottle containing the bag (A) and to the spirometer. This tube had cross wires inserted at intervals of $30 \mathrm{~cm}$. in order to produce a turbulent flow of gas in the tube (8). The mouthpiece and valve assembly had a dead space of $35 \mathrm{ml}$. The procedure for fractional measurement of the diffusing capacity was similar to that described by Ogilvie (5), but the expiration after the 10 seconds breath holding was as full as possible, and immediately on its completion the tap $\left(T_{2}\right)$ was turned to shut off the gas in the tube (C). Samples were taken from three points along the tube at known volumes from the mouthpiece by piercing the rubber tube with wide bore needles attached to well-oiled $50 \mathrm{ml}$. syringes. At each point two samples were withdrawn simultaneously. The samples were first withdrawn at the distal end of the tube. The volume along the tube at which these samples were taken was determined by the volume of gas expired. A second pair of samples was withdrawn at an intermediate point along the tube and a third pair of samples from just beyond the tap $\left(T_{2}\right)$. The samples taken at each point of the tube were analyzed for $\mathrm{CO}$ and helium. The gas mixture inspired contained 14 per cent helium, 1 per cent $C O$, 20 per cent $\mathrm{O}_{2}$ and the remainder nitrogen. The high percentage of $\mathrm{CO}$ was necessary because the $\mathrm{CO}$ samples had to be diluted to a volume large enough to completely flush the analysis tube of the infra-red $\mathrm{CO}$ meter. Preliminary experiments had shown that concentrations of $\mathrm{CO}$ in the inspired air as high as 3 per cent had no effect on $D_{L}$ measured by the single breath method. The syringes were calibrated to within $0.1 \mathrm{ml}$. by weighing the water that they could deliver. The $\mathrm{CO}$ concentration of the sample was measured by diluting $50 \mathrm{ml}$. of gas from the syringe with air in a vessel of $668 \mathrm{ml}$. capacity. After allowing an interval for mixing, the diluted gas was displaced by water and passed through the $\mathrm{CO}$ meter. The helium concentration was measured by passing the gas from the syringe through a small soda lime scrubber and through a katharometer.

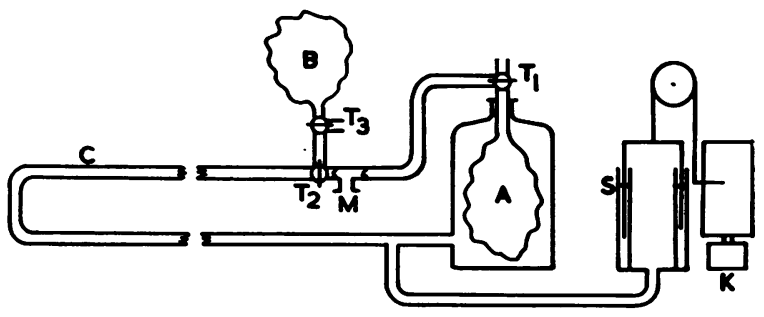

Fig. 1. Diagram of the Apparatus for Measurement of $D_{L}$ With Fractional Analysis of the ExPIRED AIR

A, bag containing the gas mixture to be inspired; $\mathrm{B}$, bag for collecting the expired gas in the steady state; C, tube in which the expired air is held prior to sampling; $M$, mouthpiece; $T_{1}, T_{2}, T_{3}$, three-way taps; $S$, spirometer; $\mathrm{K}$, kymograph.

Calculation of $D_{L}$ was made in the usual manner for each set of samples. The time that had elapsed between the beginning of the inspiration and the expiration of the sample was measured from the kymograph tracing. The lung volume used in the calculation was the same for each sample, namely the volume during breath holding. This fractional measurement of $D_{\mathbf{L}}$ was carried out first in the usual way with a full inspiration from the residual volume; it was repeated with an inspiration of moderate depth (usually about 1.5 liters) taken from the F.R.C.

Measurement of the steady state $D_{L}$ with fractional analysis of the alveolar air. The apparatus used was similar to that shown in Figure 1 except that the bag (A) and aspirating bottle were replaced by a rubberized gabardine bag of 80 liters capacity containing the gas mixture to be breathed. On the side arm of the tap $\mathrm{T}_{2}$ was attached another rubberized gabardine bag (B) and three-way tap $\left(T_{3}\right)$. The taps $T_{2}$ and $T_{3}$ were turned so that at the start of the experiment the subject expired to the atmosphere through the side arm of tap $T_{3}$. Before the start of the experiment an equilibration sample was obtained by breath holding or rebreathing as described previously. The procedure during the experiment was as follows: The subject breathed a mixture of approximately 0.5 per cent $\mathrm{CO}$ in air and expired to the atmosphere through $T_{2}$. The patients were allowed to breathe at their normal respiratory rates but the normal subjects breathed to a metronome at 12 respirations per minute. This was done because some normal subjects, when breathing quietly, have a small tidal volume, but usually have a larger tidal volume when breathing in time to a metronome. A tidal volume of about $600 \mathrm{ml}$. is necessary to wash out the dead space so that the end tidal sample consists of alveolar air. Two and one-half minutes were allowed for a steady state to be established in the lungs. Tap $T_{3}$ was turned to collect the expired gas in bag B and the gas collected for a measured time, usually one and one-half minutes. During this period of collection the respirations were counted and end tidal samples of approximately $10 \mathrm{ml}$. of gas were taken from just beyond the expiratory valve during each inspiration. 
The sample for analysis of $\mathrm{CO}$ was taken into an oiled $50 \mathrm{ml}$. syringe and a sample for analysis of $\mathrm{CO}_{2}$ and $\mathrm{O}_{2}$ was taken into a $20 \mathrm{ml}$. syringe lubricated with a saturated solution of lithium chloride. At the end of the period of gas collection the tap $T_{8}$ was turned for the patient to expire to the atmosphere and a few breaths later the kymograph was started and the tap $T_{2}$ was turned to connect tube $C$. At the next inspiration the subject was instructed to expire fully and forcibly. The patients with emphysema started their full expiration at the height of an inspiration but normal subjects started it after a normal expiration. As soon as the expiration was complete, tap $T_{2}$ was turned to close off the tube $C$ and samples were taken from the tube for analysis of $\mathrm{CO}, \mathrm{CO}_{2}$ and $\mathrm{O}_{2}$. The samples were analyzed for $\mathrm{CO}$ as described above and for $\mathrm{CO}_{2}$ and $\mathrm{O}_{2}$ using the Scholander gas analysis apparatus. Equilibration samples were again obtained, half a minute after the $\mathrm{CO}$ breathing from the normal subjects and one minute after the end of the $\mathrm{CO}$ breathing from the emphysema patients.

Calculation of the mean alveolar $\mathrm{CO}$ by a modification of Filley's method. The mean alveolar $\mathrm{CO}$ was calculated from the mixed venous $\mathrm{pCO}_{2}$ of the last five patients studied. Sivertson and Fowler (9) have shown that after a period of 16 to 20 seconds of breath holding the expired air, in patients with emphysema, contains a uniform concentration of $\mathrm{CO}_{2}$. This concentration is apparently the same as the mixed venous $\mathrm{CO}_{2}$. In this investigation equilibration with mixed venous blood was carried out by rebreathing for 20 seconds from a bag containing 1 liter of alveolar air. This alveolar air had been obtained after a previous 20 second rebreathing period. The rebreathing was carried out immediately after the patient had completed the full expiration into the frac- tional analysis tube at the end of the period of steady state breathing. The assumptions which must be made in order to calculate the end capillary $\mathrm{pCO}_{2}$ are the cardiac output and the $\mathrm{pH}$ of the blood. In this study a cardiac output of 6 liters per minute, a $\mathrm{pH}$ of 7.41 for the mixed venous blood, and a $\mathrm{pH}$ of 7.39 for the arterial blood have been assumed. The arteriovenous difference in $\mathrm{CO}_{2}$ content is calculated from the measured $\mathrm{CO}_{2}$ output during the steady state breathing and from the assumed cardiac output. The end capillary $\mathrm{pCO}_{2}$ is calculated using the nomograph of Dill, Edwards, and Consolazio (10). Since the assumed values of cardiac output and $\mathrm{pH}$ affect only the arteriovenous difference of $\mathrm{pCO}_{2}$, which is usually in the region of 5 or $6 \mathrm{~mm} . \mathrm{Hg}$, reasonable variations in the assumed values for cardiac output and $\mathrm{pH}$ will produce errors of only 1 or $2 \mathrm{~mm}$. $\mathrm{Hg}$ in the end capillary $\mathrm{pCO}_{2}$, errors which are no greater than the experimental error of direct measurement of arterial $\mathrm{pCO}_{2}$.

Fractional analysis of the expired air for helium. This procedure was carried out using the apparatus shown in Figure 1. A 14 per cent helium mixture in air was inspired and expired immediately into the tube. Samples were taken at intervals along the tube. Fractional analysis of the expirate was carried out: a) after a full inspiration from the residual volume, and $b$ ) after an inspiration of about 1.5 liters from the F.R.C. Procedure b) was done in order to measure the distribution of helium in the alveolar air after a breath similar to an ordinary inspiration.

The lung volume of all subjects was measured by closed circuit spirometry and by the helium dilution method of Bates and Christie (11). The results were corrected to B.T.P.S.

TABLE I

Physical data on five normal subjects and eleven patients with emphysema

\begin{tabular}{|c|c|c|c|c|c|c|c|c|}
\hline Subject & Age & Sex & Height & Weight & B.S.A.* & F.R.C. $†$ & R.V.t & V.C.8 \\
\hline Normal & years & & $\mathrm{cm}$ & $K_{g}$. & $M . .^{2}$ & $L$. & $L$. & $L$. \\
\hline $\begin{array}{l}\text { A. B. } \\
\text { R. W. } \\
\text { R. M. } \\
\text { M. E. } \\
\text { P. R. }\end{array}$ & $\begin{array}{l}26 \\
28 \\
34 \\
19 \\
19\end{array}$ & $\begin{array}{l}\mathbf{M} \\
\mathbf{M} \\
\mathbf{M} \\
\mathbf{F} \\
\mathbf{F}\end{array}$ & $\begin{array}{l}168 \\
185 \\
176 \\
161 \\
165\end{array}$ & $\begin{array}{l}60.8 \\
71.0 \\
75.4 \\
47.7 \\
54.9\end{array}$ & $\begin{array}{l}1.66 \\
1.93 \\
1.95 \\
1.47 \\
1.59\end{array}$ & $\begin{array}{l}3.39 \\
6.72 \\
3.86 \\
3.33 \\
2.54\end{array}$ & $\begin{array}{l}1.98 \\
3.83 \\
1.69 \\
2.08 \\
1.50\end{array}$ & $\begin{array}{l}4.41 \\
6.52 \\
5.77 \\
3.50 \\
3.53\end{array}$ \\
\hline $\begin{array}{l}\text { Emphysema } \\
\text { P. F. } \\
\text { G. E. } \\
\text { T. F. } \\
\text { R. R. } \\
\text { A. G. } \\
\text { J. T. } \\
\text { H. B. } \\
\text { J. L. } \\
\text { P. C. } \\
\text { F. B. } \\
\text { S. R. }\end{array}$ & $\begin{array}{l}53 \\
63 \\
64 \\
51 \\
63 \\
61 \\
62 \\
56 \\
53 \\
58 \\
64\end{array}$ & $\begin{array}{l}\mathbf{M} \\
\mathbf{M} \\
\mathbf{M} \\
\mathbf{M} \\
\mathbf{M} \\
\mathbf{M} \\
\mathbf{M} \\
\mathbf{M} \\
\mathbf{M} \\
\mathbf{M} \\
\mathbf{M}\end{array}$ & $\begin{array}{l}173 \\
169 \\
178 \\
180 \\
170 \\
168 \\
165 \\
174 \\
173 \\
163 \\
163\end{array}$ & $\begin{array}{l}60.2 \\
68.5 \\
63.5 \\
78.0 \\
46.2 \\
56.2 \\
69.8 \\
51.4 \\
56.8 \\
57.3 \\
59.1\end{array}$ & $\begin{array}{l}1.72 \\
1.78 \\
1.79 \\
1.97 \\
1.52 \\
1.63 \\
1.77 \\
1.61 \\
1.67 \\
1.61 \\
1.62\end{array}$ & $\begin{array}{l}6.61 \\
5.06 \\
3.94 \\
5.70 \\
6.12 \\
4.24 \\
3.17 \\
5.66 \\
4.73 \\
3.64 \\
3.98\end{array}$ & $\begin{array}{l}5.83 \\
4.58 \\
3.43 \\
5.12 \\
5.50 \\
3.81 \\
2.69 \\
4.70 \\
3.70 \\
3.14 \\
3.45\end{array}$ & $\begin{array}{l}1.95 \\
1.96 \\
2.37 \\
2.32 \\
2.39 \\
2.04 \\
2.10 \\
3.34 \\
3.20 \\
2.48 \\
1.74\end{array}$ \\
\hline
\end{tabular}

* Body surface area.

† Functional residual capacity.

$¥$ Residual volume.

$\$$ Vital capacity. 
TABLE II

Fractional analysis of helium concentration in the expired air: Expiration immediately after end of inspiration

\begin{tabular}{|c|c|c|c|c|c|c|c|c|c|c|}
\hline \multirow[b]{3}{*}{ Subject } & \multirow{3}{*}{$\begin{array}{l}\text { Inspiration } \\
\text { taken } \\
\text { from }\end{array}$} & \multicolumn{9}{|c|}{ Per cent helium } \\
\hline & & \multicolumn{9}{|c|}{ Volume of sample from mouth at end of expiration (liters) } \\
\hline & & 4.0 & 3.5 & 3.0 & 2.5 & 2.0 & 1.5 & 1.0 & 0.5 & 0.2 \\
\hline \multicolumn{11}{|l|}{ Normal } \\
\hline A. B. & $\begin{array}{l}\text { R.V.V* } \\
\text { F.R.C. } \dagger\end{array}$ & & 11.2 & 3.53 & & 10.94 & 3.41 & & & $\begin{array}{r}11.08 \\
3.17\end{array}$ \\
\hline R. W. & $\begin{array}{l}\text { R.V. } \\
\text { F.R.C. }\end{array}$ & 9.36 & & 2.98 & & 9.00 & 2.78 & & & $\begin{array}{l}8.67 \\
2.63\end{array}$ \\
\hline R. M. & $\begin{array}{l}\text { R.V. } \\
\text { F.R.C. }\end{array}$ & & 11.50 & & 3.06 & 11.35 & & 2.58 & & $\begin{array}{r}10.67 \\
2.40\end{array}$ \\
\hline M. E. & $\begin{array}{l}\text { R.V. } \\
\text { F.R.C. }\end{array}$ & & & & 8.48 & 4.80 & & $\begin{array}{l}8.25 \\
4.65\end{array}$ & & $\begin{array}{l}8.06 \\
4.35\end{array}$ \\
\hline P. R. & $\begin{array}{l}\text { R.V. } \\
\text { F.R.C. }\end{array}$ & & & 11.58 & 6.98 & & 11.35 & 6.77 & & $\begin{array}{r}11.33 \\
6.57\end{array}$ \\
\hline \multicolumn{11}{|c|}{ Emphysema } \\
\hline P.F. & $\begin{array}{l}\text { R.V. } \\
\text { F.R.C. }\end{array}$ & & & & & $\begin{array}{l}9.98 \\
6.56\end{array}$ & & $\begin{array}{l}7.17 \\
4.37\end{array}$ & & $\begin{array}{l}5.73 \\
3.38\end{array}$ \\
\hline G. E. & $\begin{array}{l}\text { R.V. } \\
\text { F.R.C. }\end{array}$ & & & & & & $\begin{array}{l}9.30 \\
5.92\end{array}$ & $\begin{array}{l}8.43 \\
5.18\end{array}$ & & $\begin{array}{l}6.58 \\
3.72\end{array}$ \\
\hline T. F. & $\begin{array}{l}\text { R.V. } \\
\text { F.R.C. }\end{array}$ & & & & & 10.03 & 6.98 & $\begin{array}{l}9.08 \\
5.50\end{array}$ & & $\begin{array}{l}7.82 \\
3.75\end{array}$ \\
\hline R. R. & $\begin{array}{l}\text { R.V. } \\
\text { F.R.C. }\end{array}$ & & & & 7.42 & 8.48 & 6.40 & 7.30 & & $\begin{array}{l}6.17 \\
4.57\end{array}$ \\
\hline A. G. & $\begin{array}{l}\text { R.V.V. } \\
\text { F.R.C. }\end{array}$ & & & & & $\begin{array}{l}9.22 \\
4.28\end{array}$ & & $\begin{array}{l}7.68 \\
2.95\end{array}$ & & $\begin{array}{l}6.23 \\
2.07\end{array}$ \\
\hline J. T. & $\begin{array}{l}\text { R.V. } \\
\text { F.R.C. }\end{array}$ & & & & & & 10.43 & $\begin{array}{l}9.27 \\
6.62\end{array}$ & 5.72 & $\begin{array}{l}8.13 \\
4.73\end{array}$ \\
\hline H. B. & $\begin{array}{l}\text { R.V. } \\
\text { F.R.C. }\end{array}$ & & & & & $\begin{array}{l}8.77 \\
5.91\end{array}$ & & $\begin{array}{l}8.12 \\
5.23\end{array}$ & & $\begin{array}{l}7.28 \\
4.19\end{array}$ \\
\hline J. L. & $\begin{array}{l}\text { R.V. } \\
\text { F.R.C. }\end{array}$ & & & & 11.0 & 5.83 & & $\begin{array}{l}7.97 \\
3.60\end{array}$ & & $\begin{array}{l}6.58 \\
2.50\end{array}$ \\
\hline P. C. & $\begin{array}{l}\text { R.V. } \\
\text { F.R.C. }\end{array}$ & & & & & $\begin{array}{l}9.80 \\
5.53\end{array}$ & & $\begin{array}{l}9.30 \\
4.62\end{array}$ & & $\begin{array}{l}8.48 \\
4.04\end{array}$ \\
\hline F. B. & $\begin{array}{l}\text { R.V. } \\
\text { F.R.C. }\end{array}$ & & & & & $\begin{array}{r}10.60 \\
6.34\end{array}$ & & $\begin{array}{l}9.51 \\
4.77\end{array}$ & & $\begin{array}{l}7.97 \\
3.58\end{array}$ \\
\hline S. R. & $\begin{array}{l}\text { R.V. } \\
\text { F.R.C. }\end{array}$ & & & & & & $\begin{array}{l}5.40 \\
5.95\end{array}$ & $\begin{array}{l}4.78 \\
4.62\end{array}$ & & $\begin{array}{l}3.36 \\
2.47\end{array}$ \\
\hline
\end{tabular}

* Residual volume.

† Functional residual capacity.

RESULTS

The investigations were carried out on 5 normal subjects and 11 patients with emphysema. The physical data and lung volumes of these subjects are shown in Table $I$.
A. Distribution of helium in the lungs after a single breath

The results for the normal subjects and the patients with emphysema are shown in Table II. These experiments were carried out to investigate 


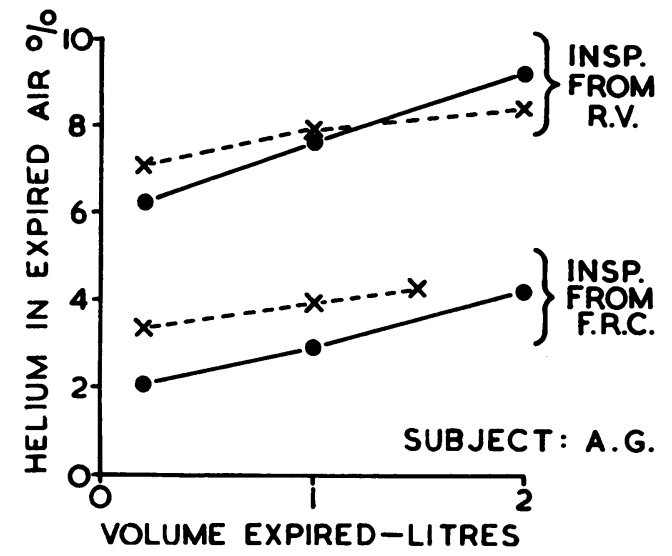

Fig. 2. Distribution of Helium in the Expired Air After a Single Breath From the Residual Volume (R.V.) or From the Functional Residual Capacity (F.R.C.) (PAtient With Emphysema)

, expiration immediately after the inspiration; $X$, expiration after breath holding for 10 seconds.

the gas distribution in the lungs of the subjects and to compare the distribution after large breaths from the residual volume (as in the single breath test) and inspiration of a moderate sized breath from the F.R.C. (as in the steady state tests).

TABLE III

Measurement of $D_{L}$ by the single breath method

\begin{tabular}{|c|c|c|c|}
\hline Subject & $\begin{array}{c}\text { Predicted } \\
D_{L}\end{array}$ & $\begin{array}{c}\text { Lung } \\
\text { volume }\end{array}$ & $\mathrm{D}_{\mathrm{L}}$ \\
\hline \multicolumn{4}{|c|}{ ml. $/ \mathrm{min} . / \mathrm{mm} . \mathrm{Hg} \quad$ liters B.T.P.S. $\quad$ ml. $/ \mathrm{min} . / \mathrm{mm} . \mathrm{Hg}$} \\
\hline A. B. & 24.5 & $\begin{array}{l}7.31 \\
4.46\end{array}$ & $\begin{array}{l}40.7 \\
30.8\end{array}$ \\
\hline R. W. & 29.6 & $\begin{array}{l}9.70 \\
7.00\end{array}$ & $\begin{array}{r}48.6 \\
.36 .6\end{array}$ \\
\hline R. M. & 30.0 & $\begin{array}{l}7.41 \\
4.50\end{array}$ & $\begin{array}{l}31.1 \\
24.7\end{array}$ \\
\hline M. E. & 20.9 & $\begin{array}{l}5.05 \\
3.59\end{array}$ & $\begin{array}{l}25.2 \\
21.9\end{array}$ \\
\hline P. R. & 23.0 & $\begin{array}{l}4.99 \\
2.99\end{array}$ & $\begin{array}{l}26.6 \\
23.3\end{array}$ \\
\hline \multicolumn{4}{|c|}{ Emphysema } \\
\hline $\begin{array}{l}\text { P. F. } \\
\text { G. E. } \\
\text { T. F. } \\
\text { R. R. } \\
\text { A. G. } \\
\text { J. T. } \\
\text { H. B. } \\
\text { J. L. } \\
\text { P. C. } \\
\text { F. B. } \\
\text { S. R. }\end{array}$ & $\begin{array}{l}25.6 \\
26.8 \\
27.0 \\
30.2 \\
21.9 \\
23.9 \\
27.9 \\
23.5 \\
24.7 \\
23.5 \\
23.7\end{array}$ & $\begin{array}{l}8.13 \\
7.23 \\
5.90 \\
7.92 \\
8.79 \\
6.04 \\
6.04 \\
7.82 \\
7.38 \\
5.94 \\
5.16\end{array}$ & $\begin{array}{r}9.0 \\
25.5 \\
8.3 \\
25.0 \\
18.1 \\
23.6 \\
20.0 \\
10.7 \\
19.8 \\
18.8 \\
21.7\end{array}$ \\
\hline
\end{tabular}

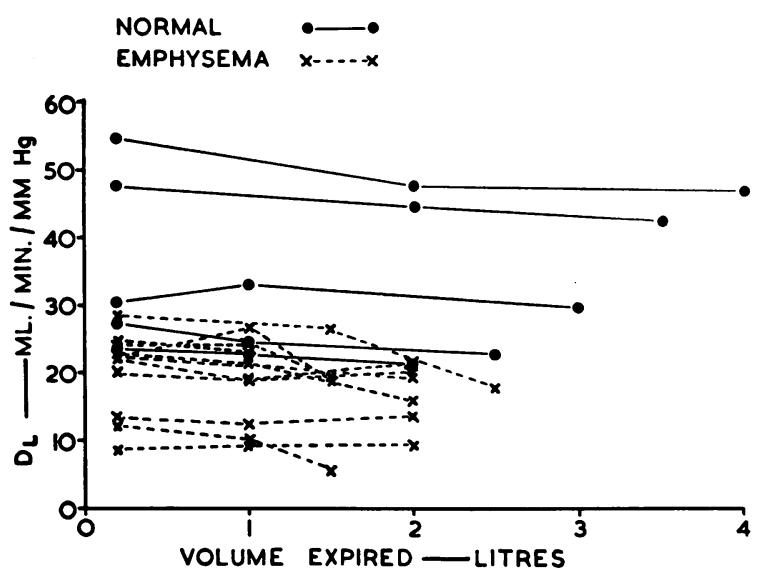

Fig. 3. Variations in $D_{\mathrm{L}}$ in Different Fractions of the Expired Air After Breath Holding for 10 SECONDS

The effect of 10 seconds breath holding on the distribution of inspired gas was also investigated. The normal subjects had an almost even distribution of gas with both types of inspiration. The patient with emphysema showed uneven distribution of the inspired helium with both types of inspiration. Breath holding for 10 seconds reduced, but did not abolish, the uneven gas distribution (Figure 2).

\section{$B$. Single breath $D_{L}$ measurements}

The results of these measurements are shown in Table III. Six of the eleven patients with

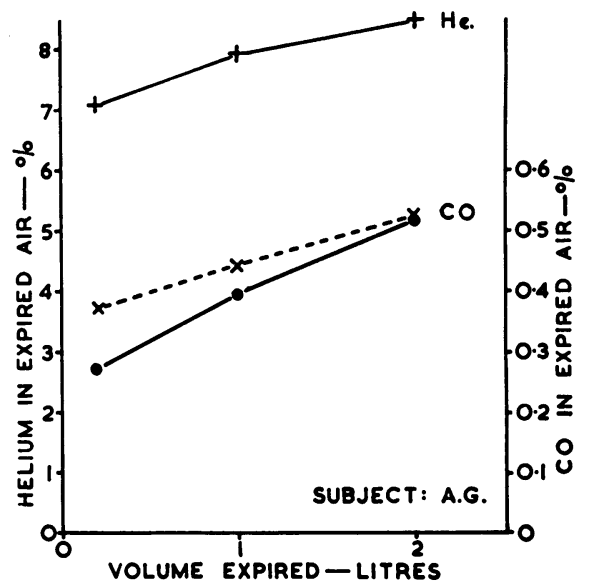

Fig. 4. The Concentrations of CO and Helium in the Different Fractions of the Expired Air of a Patient With Emphysema After Breath Holding FOR 10 SECONDS

- $\mathrm{CO}$ concentration measured in the expired air; $\times$, $\mathrm{CO}$ concentration corrected for the time required for expiration. 
emphysema had a single breath $D_{\mathbf{L}}$ within one standard error of the normal value predicted by the formula of Ogilvie and associates (5).

\section{Fractional measurement of $D_{L}$ by the single breath method}

The results obtained in these experiments are shown in Table IV and in Figures 3 and 4. There was no appreciable difference in the results obtained with breath holding after a full inspiration from the residual volume and those obtained with an inspiration from the F.R.C. of about 1.5 liters. The $D_{\mathrm{L}}$ of the fractional samples of the alveolar gas of the normal subjects shows a small rise in the later expired samples in some of the subjects but in most $D_{\mathbf{L}}$ is approximately uniform throughout expiration. ${ }^{3}$ Similar results were obtained

3 The later expired samples contain less $\mathrm{O}_{2}$ and this will increase the $D_{L}$ of these samples, but the effect is small. For example, if the early expired sample contains 17 per cent $\mathrm{O}_{2}(\theta=0.71)$ and the later expired one 14 per cent $\mathrm{O}_{2}(\theta=0.77)(12)$, and if $\mathrm{D}_{\mathbf{u}}=60 \mathrm{ml}$./

TABLE IV

Single breath $D_{L}$ with fractional analysis of the expired air

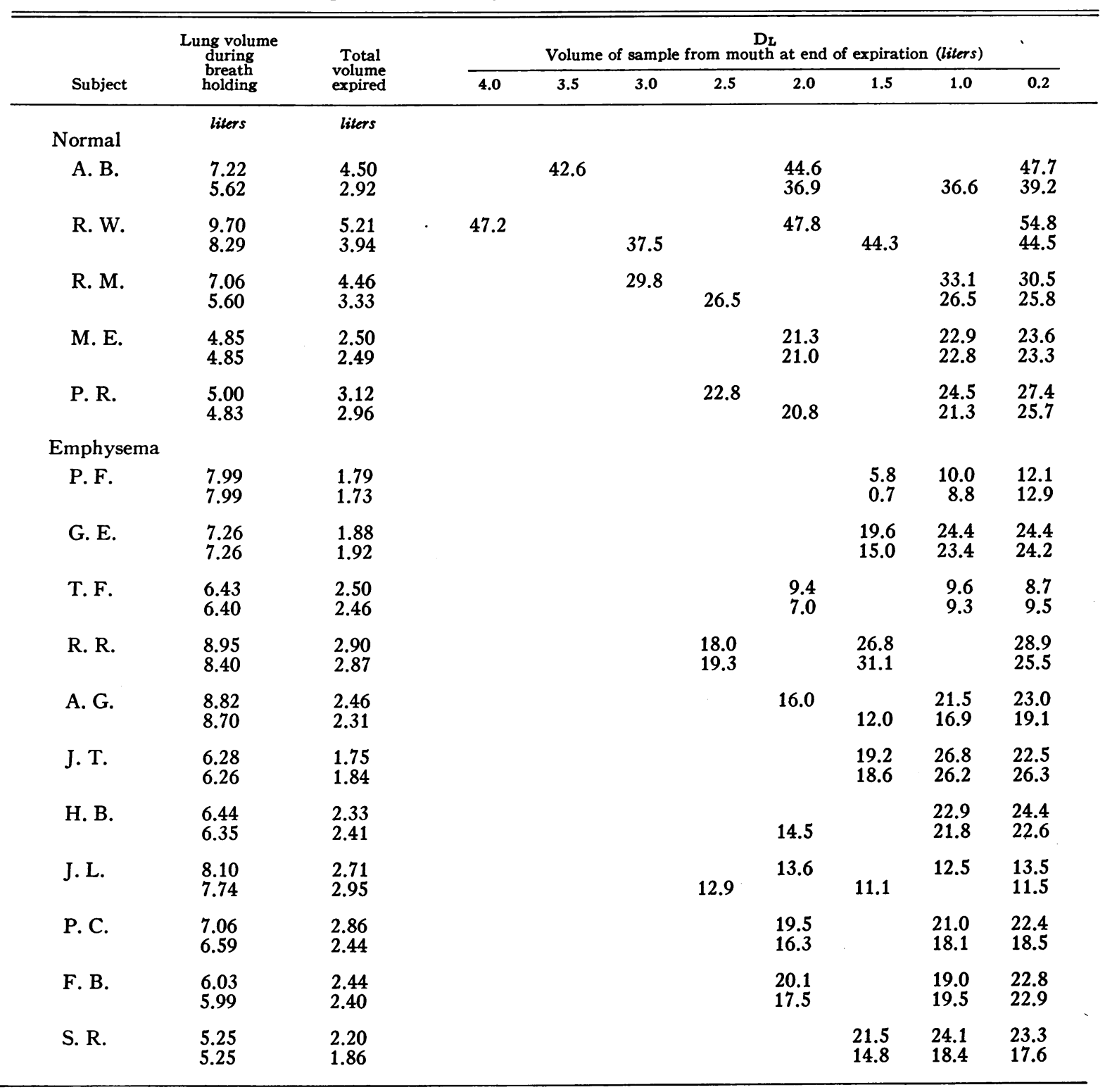


TABLE V

The steady state $D_{L}$ with fractional analysis of a full expiration: Normal subjects

\begin{tabular}{|c|c|c|c|c|c|c|c|c|c|c|c|c|c|}
\hline \multirow[b]{3}{*}{ Subject } & \multirow{3}{*}{$\begin{array}{l}\text { Minute } \\
\text { volume } \\
(L .)\end{array}$} & \multirow{3}{*}{$\begin{array}{c}\text { Resp. } \\
\text { per } \\
\text { min. }\end{array}$} & \multirow{2}{*}{\multicolumn{3}{|c|}{ End tidal gas (\%) }} & \multirow{2}{*}{\multicolumn{3}{|c|}{ Mixed expired gas (\%) }} & \multirow{3}{*}{$\begin{array}{c}\text { Vol. of } \\
\text { sample } \\
\text { from } \\
\text { mouth } \\
(L .)\end{array}$} & \multicolumn{2}{|c|}{$\begin{array}{l}\text { Fractional } \\
\text { sample }\end{array}$} & \multicolumn{2}{|c|}{$\begin{array}{c}D_{L} \text { calculated } \\
\text { from }\end{array}$} \\
\hline & & & & & & & & & & & $\mathrm{CO}$ & & \\
\hline & & & $\mathrm{CO}_{2}$ & $\mathrm{O}_{2}$ & $\mathrm{CO}$ & $\mathrm{CO}_{2}$ & $\mathrm{O}_{2}$ & $\mathrm{CO}$ & & $\mathrm{CO}$ & for time & tidal & sample \\
\hline A. B. & 11.0 & 12 & 4.77 & 16.56 & 0.1861 & 3.42 & 17.84 & 0.2769 & $\begin{array}{l}3.0 \\
2.0 \\
1.0 \\
0.2\end{array}$ & $\begin{array}{l}0.2218 \\
0.2039 \\
0.1883 \\
0.1736\end{array}$ & $\begin{array}{l}0.2043 \\
0.2172 \\
0.2160 \\
0.2220\end{array}$ & 27.4 & 22.7 \\
\hline R. W. & 10.9 & 12 & 5.39 & 15.12 & 0.1011 & 3.48 & 17.51 & 0.1995 & $\begin{array}{l}2.5 \\
1.5 \\
1.0 \\
0.2\end{array}$ & $\begin{array}{l}0.0703 \\
0.0705 \\
0.0667 \\
0.0606\end{array}$ & $\begin{array}{l}0.0727 \\
0.0744 \\
0.0715 \\
0.0672\end{array}$ & 36.9 & 55.5 \\
\hline R. M. & 9.9 & 12 & 5.47 & 15.32 & 0.1212 & 3.65 & 17.02 & 0.2075 & $\begin{array}{l}3.0 \\
2.5 \\
2.0 \\
1.0 \\
0.2\end{array}$ & $\begin{array}{l}0.1214 \\
0.1084 \\
0.1072 \\
0.1045 \\
0.0976\end{array}$ & $\begin{array}{l}0.1106 \\
0.1069 \\
0.1085 \\
0.1087 \\
0.1064\end{array}$ & 22.9 & 26.6 \\
\hline M. E. & 9.3 & 12 & 4.71 & 16.95 & 0.1783 & 3.20 & 18.34 & 0.2700 & $\begin{array}{l}2.0 \\
1.5 \\
1.0 \\
0.5 \\
0.2\end{array}$ & $\begin{array}{l}0.2030 \\
0.1800 \\
0.1713 \\
0.1628 \\
0.1630\end{array}$ & $\begin{array}{l}0.1766 \\
0.1724 \\
0.1745 \\
0.1714 \\
0.1746\end{array}$ & 21.4 & 21.6 \\
\hline P. R. & 7.6 & 12 & 5.10 & 16.20 & 0.1358 & 3.79 & 17.52 & 0.1983 & $\begin{array}{l}1.5 \\
1.0 \\
0.5 \\
0.2\end{array}$ & $\begin{array}{l}0.1278 \\
0.1084 \\
0.1020 \\
0.0942\end{array}$ & $\begin{array}{l}0.1147 \\
0.1102 \\
0.1090 \\
0.1076\end{array}$ & 19.0 & 24.4 \\
\hline
\end{tabular}

for the patients with emphysema although in some of the patients the $D_{L}$ of the first expired sample was low. These low values were due to admixture of the sample with dead space gas and occurred when the sample was taken within a few hundred $\mathrm{ml}$. of the total volume expired (see Table IV). If the early samples are excluded the patients with emphysema are seen to have a uniform $D_{\mathbf{L}}$ in the different fractions of the expired air. In these patients the time required for expiration of the last sample may be about one-third of the total breath holding time. During expiration the intrathoracic pressure is high, but Ogilvie and coworkers (5) have shown that a positive intrathoracic pressure has only a small effect on $D_{L}$. Thus, there is no evidence of large changes of diffusing capacity in different regions of the lungs of these patients, but unfortunately, owing to admixture with the dead space gas, this method is not precise enough to detect a low $D_{L}$ in the regions from which the first few hundred $\mathrm{ml}$. of expired gas originate. The word "region" is used

minute $/ \mathrm{mm}$. $\mathrm{Hg}$ and $\mathrm{V}_{\mathrm{e}}=60 \mathrm{ml}$, the $\mathrm{D}_{\mathrm{L}}$ of the early sample is $24.9 \mathrm{ml} . / \mathrm{minute} / \mathrm{mm}$. $\mathrm{Hg}$, and of the later sample $26.1 \mathrm{ml} . / \mathrm{minute} / \mathrm{mm}$. $\mathrm{Hg}$. here to denote the site of origin of the gas which is expired at any particular time of expiration and does not necessarily denote an anatomical division of the lungs.

\section{$D$. The steady state $D_{L}$ with fractional analysis of the alveolar air}

The results obtained in these experiments are shown in Tables V and VI. The concentration of $\mathrm{CO}$ in the expired air of the subjects was corrected for the time required for expiration, assuming that $\mathrm{CO}$ was taken up at the rate denoted by the single breath $D_{L}$ measured with the breath held at the F.R.C. (see Appendix). The relationship between the corrected $\mathrm{CO}$ concentration and the expired volume of a normal subject is shown in Figure 5. It can be seen that the concentration of $\mathrm{CO}$ is uniform throughout the lung. The end tidal sample is rather high in relation to the fractional alveolar samples in four of the five normal subjects despite the moderately large tidal volumes and the use of a valve assembly with a small dead space $(35 \mathrm{ml}$.). This difference is probably produced by the subject taking a larger 
MEASUREMENT OF DIFFUSING CAPACITY OF THE LUNGS

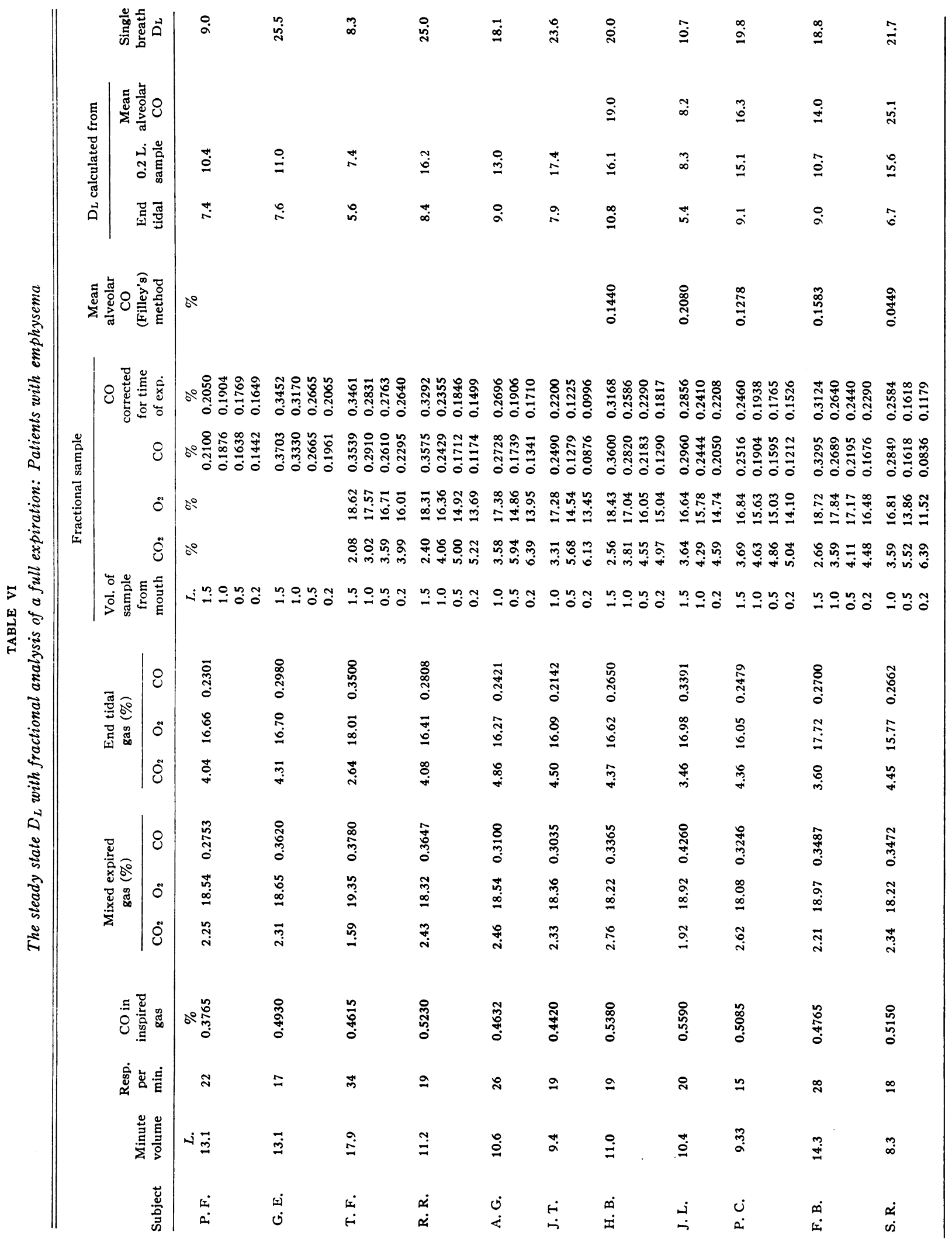




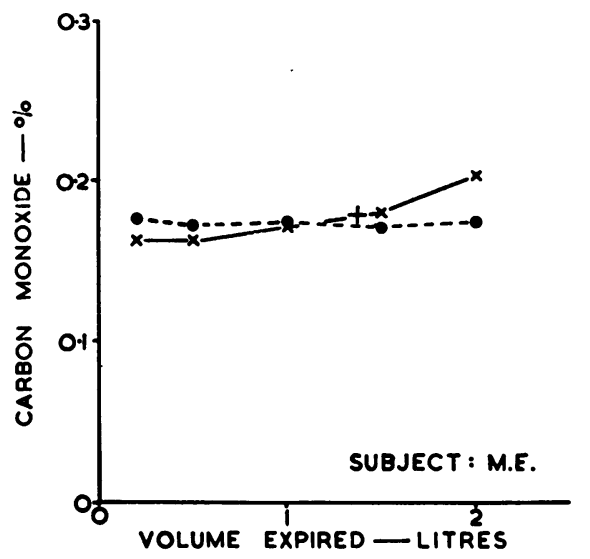

Fig. 5. Concentration of CO in Fractions of the Expired Atr of a Normal Subject in the Steady STATE

$\times, \mathrm{CO}$ concentration measured in the expired air; $\bullet$, $\mathrm{CO}$ concentration corrected for the time required for expiration; + , end tidal sample.

breath before the final full expiration. The $D_{\mathbf{L}}$ calculated from the end tidal sample is therefore lower in most subjects than that calculated from the last expired sample, although in only one subject is this difference large.

The patients with emphysema do not have a uniform concentration of $\mathrm{CO}$ in the alveolar air (Figure 6), even when this is corrected for time. Figure 6 shows the fractional analysis for $\mathrm{CO}$ and $\mathrm{CO}_{2}$ of the expired air of Patient H.B. when this patient was in the steady state. Since the alveolar $\mathrm{CO}$ is not uniform, the end tidal CO concentration bears no relationship to the mean alveolar CO. The $D_{L}$ calculated, using the different fractional samples as measures of alveolar $\mathrm{CO}$, will vary widely. The values obtained for $D_{L}$ using a modification of Filley's method for calculating the mean alveolar $\mathrm{CO}$ are shown also in Table VI.

In the last five patients studied the ventilationperfusion ratios $(V / Q)$ have been calculated by the method of Rahn and Fenn (13) for each of the samples taken during the full expiration at the end of the steady state period. These values are shown in Table VII in the form of ratios indicating the variation of the $V / Q$ of the 1.0 liter sample to that of the last expired sample at 0.2 liter. In this table is shown also the distribution of helium in the lungs during a single breath inspired from the F.R.C. and from the residual volume. The relationship of $\mathrm{V} / \mathrm{Q}$ of the 1.0 liter sample to that of the 0.2 liter sample has been corrected for the extra time required for expiration of the 0.2 liter sample. This correction has been made on the assumption that, whereas the ventilation and perfusion of the 1.0 liter sample both occupied $60 \mathrm{sec}-$ onds and the ventilation of the 0.2 liter sample occupied 60 seconds, the perfusion of this sample occupied 60 plus $t$ seconds, where $t$ is the time interval between the expiration of the 1.0 and 0.2 liter samples. The ventilation ratio of the 1.0 and 0.2 liter samples, determined by the helium concentration of the samples after a single breath of helium, is usually less when the breath is taken from the residual volume than when the breath is taken from the F.R.C. Both of these values are shown in Table VII. Some of the values in this table have been omitted when the inspiration was taken from well above the F.R.C. The ratio of the $V / Q$ of the 1.0 liter sample to that of the 0.2 liter sample is of the same order as the ratio of the ventilation of these samples, and suggests that the perfusion per unit volume of the lung from which the two samples originate is the same.

\section{DISCUSSION}

The different values obtained for the $D_{L}$ of normal subjects by the single breath method and by the steady state method could be due to a number of factors. Forster, Fowler, and Bates (14) have pointed out that steady state methods

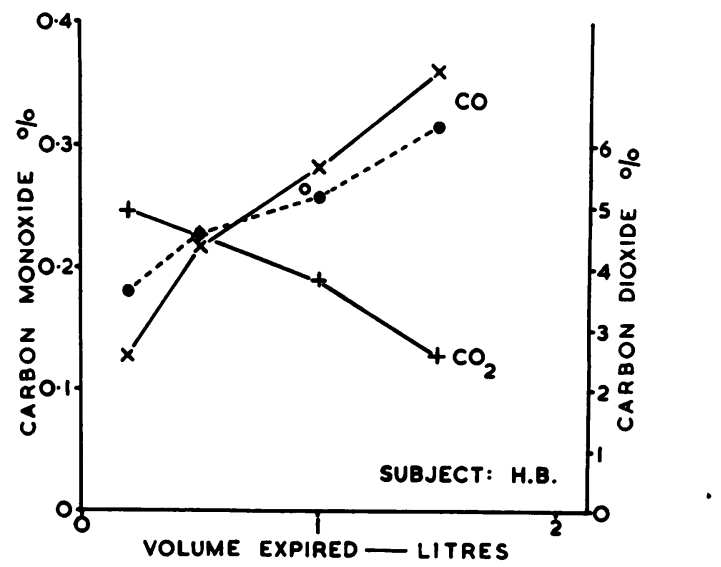

Fig. 6. Concentrations of $\mathrm{CO}$ and $\mathrm{CO}_{2}$ in Fractions of the Expired Air of a Patient With EmphySema in the Steady State

$X$, CO concentration measured in the expired air; -, $\mathrm{CO}$ concentration corrected for the time required for expiration; $O$, end tidal sample of $C O$. 
TABLE VII

Comparison between ventilation and ventilation-perfusion ratios in five patients with emphysema

\begin{tabular}{|c|c|c|c|c|c|}
\hline \multirow[b]{2}{*}{ Patient } & \multirow[b]{2}{*}{$\frac{\dot{\mathrm{V}} / \mathrm{Q} 1.0 \mathrm{~L} \text {. sample }}{\dot{\mathrm{V}} / \mathrm{Q} 0.2 \text { L. sample }}$} & \multirow{2}{*}{$\begin{array}{c}\text { Interval between } \\
\text { exp. of } 1.0 \\
\text { and } 0.2 \mathrm{~L} \text {. } \\
\text { samples (sec.) } \\
(=\mathrm{t})\end{array}$} & \multirow[b]{2}{*}{$\frac{\dot{\mathrm{V}} / Q 1.0 \mathrm{~L} .}{\dot{\mathrm{V}} / Q \mathrm{Q} 0.2 \mathrm{~L} .} \times \frac{60}{(60+\mathrm{t})}$} & \multicolumn{2}{|c|}{$\frac{\text { He \%, } 1.0 \text { L. sample }}{\text { He \%, 0.2 L. sample }}$} \\
\hline & & & & $\begin{array}{l}\text { Insp. from } \\
\text { R.V.* }\end{array}$ & $\begin{array}{c}\text { Insp. from } \\
\text { F.R.C. } t\end{array}$ \\
\hline $\begin{array}{l}\text { H. B. } \\
\text { J. L. } \\
\text { P.C. } \\
\text { F. B. } \\
\text { S. R. }\end{array}$ & $\begin{array}{l}1.36 \\
1.20 \\
1.31 \\
1.31 \\
1.44\end{array}$ & $\begin{array}{l}6.26 \\
3.44 \\
4.66 \\
5.19 \\
6.34\end{array}$ & $\begin{array}{l}1.23 \\
1.13 \\
1.22 \\
1.21 \\
1.30\end{array}$ & $\begin{array}{l}1.13 \\
1.21 \\
1.10 \\
1.19 \\
1.42\end{array}$ & $\begin{array}{c}1.25 \\
\ddagger \\
1.25 \\
1.33 \\
\ddagger\end{array}$ \\
\hline
\end{tabular}

* Residual volume.

$\dagger$ Functional residual capacity.

$\ddagger$ These patients started the inspiration from a level considerably above the F.R.C.

may give inaccurate results if there is a disproportion between ventilation and diffusion of different parts of the lung. In normal subjects this and previous investigations (15) have shown that the ventilation is approximately uniform after a single breath of a foreign gas. The $D_{L}$ has also been found to be uniform throughout the expired air; thus, in normal subjects unevenness of ventilation and diffusion cannot be the cause of the difference in results by the two methods and further examination of the methods is necessary.

The steady state method using end tidal samples as a measure of the mean alveolar concentration of $C O\left(F_{\overline{\mathbf{A} c o}}\right)$

In this method $D_{L}$ is calculated by the following equation:

$$
\mathrm{D}_{\mathrm{L}}=\frac{\text { uptake of } \mathrm{CO}(\mathrm{ml} \text {. per minute })}{\mathrm{F}_{\overline{\mathrm{A}} \mathrm{co}} \times(\mathrm{B}-47)} .
$$

The uptake of $\mathrm{CO}$ can be measured accurately as the difference between the $\mathrm{CO}$ inspired and that expired. $F_{\bar{A} \mathbf{~ o o}}$ can be measured in normal subjects by the use of end tidal samples (Figure 5) provided that the tidal volume is $600 \mathrm{ml}$. or more, so that complete washout of the dead space can take place, and the instrumental dead space is small. Previous experience with a valve assembly having a dead space of $65 \mathrm{ml}$, which was of irregular shape and therefore not easily flushed out, showed that with this valve assembly true end tidal samples may not be obtained even with a tidal volume of 1 liter. The concentration of $\mathrm{CO}_{2}$ in the alveolar gas at the end of a normal expiration lies between the maximum and minimum concentrations which are reached during the re- spiratory cycle (16). The end tidal sample of 60 will also lie between the maximum and minimum levels, rather closer to the minimum level, so that the value of $F_{A_{c o}}$ will be too low and the resultant $D_{\mathbf{L}}$ will tend to be too high.

\section{The single breath method}

The equation on which this method is based is as follows :

$$
D_{L}=\frac{\ln . \frac{F_{\text {INco }}}{F_{\mathrm{Eco}}} \times V_{A} \times 60}{t \times(B-47)},
$$

where $F_{I N c o}$ is the initial concentration of $C O$ in the lungs, $F_{E c o}$ is the concentration expired after time $t$ seconds, $V_{\mathbf{A}}$ (ml. S.T.P.D.) is the alveolar volume, and $\mathrm{B}$ is the barometric pressure in $\mathrm{mm}$. $\mathrm{Hg}$.

The term $\frac{\ln . \frac{F_{\mathrm{INco}}}{F_{\mathrm{Eeo}}}}{t}$ is the slope of alveolar concentration of $\mathrm{CO}$ plotted against time and in these experiments has been measured over the interval of 0 to 10 seconds. Forster, Fowler, Bates, and Van Lingen (17) have reported that this initial slope may be two to five times greater than between 40 and 60 seconds when the breath is held. This non-linearity of the logarithmic decay curve has been ascribed by Forster and co-workers (17) to variations in the diffusing capacity per unit gas volume throughout the lung. Since, in normal subjects, the ventilation and the $D_{\mathbf{L}}$ are approximately uniform in different fractions of the expired air, it is surprising if marked differences in diffusing capacities per unit lung volume exist. The experiment of breath holding for different 


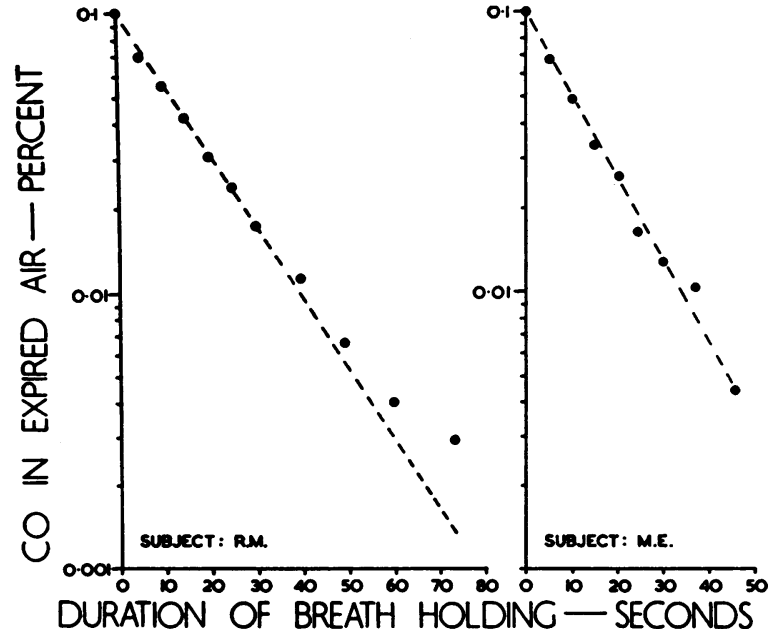

Fig. 7. The Disappearance of CO From the Lungs of Normal Subjects Who Are Breath Holding at the Full INSPIRATORY Position

times has been repeated in Subjects R.M. and M.E. with the results shown in Figure 7. The breath was held at full inspiration and correction has been made at each point for the back pressure of $\mathrm{CO}$ existing in the blood. In Subject M.E. the $\mathrm{CO}$ concentration falls exponentially with time up to the limit of breath holding (45 seconds). Measurements have been made on Subject R.M. on many occasions with the breath held at full inspiration and also at the F.R.C. When the breath is held at the F.R.C. the fall of $\mathrm{CO}$ concentration with time is exponential up to the limit of breath holding (about 35 seconds) but with breath holding at full inspiration the fall of $\mathrm{CO}$ concentration usually deviates from the straight line at 25 or 30 seconds. This deviation is small in terms of percentage of $\mathrm{CO}$ measured and in the experiment illustrated in Figure 7 the concentrations did not vary by more than 0.002 per cent from the values lying on the straight line. This small difference could well be due to an error in calculation of the back pressure of $\mathrm{CO}$ in the blood as a result of the recirculation of blood previously exposed to $\mathrm{CO}$ in the lungs. These results do not support the findings of Forster and associates (17). Thus, there appears to be no need to postulate variations in the diffusing capacity per unit volume of the lungs of normal subjects, and such a variation of diffusing capacity is unlikely to be the cause of the different results obtained by the single breath and steady state methods of measuring $D_{L}$. The single breath method has been criticized on the grounds that a sudden inspiration may alter the diffusing capacity of the lungs. The fact that the rate of fall of $\mathrm{CO}$ concentration during the first few seconds after inspiration is the same as that throughout the remainder of the breath holding time refutes this criticism.

One of the outstanding differences in the techniques of the single breath and the steady state methods is the lung volume at which the measurements are made. Krogh (18) reported that $D_{\mathbf{L}}$ increased proportionately to alveolar volume at volumes above the "mean capacity." Ogilvie and co-workers (5) found that the increase in $D_{L}$ was only about 9 per cent for an increase in lung volume of 56 per cent, although three of their five subjects had increases of $D_{L}$ of 13,18 and 24 per cent. In the present investigation the mean increase in $\mathrm{D}_{\mathrm{L}}$ was 24 per cent when the lung volume increased by 56 per cent. Figure 8 shows the $D_{L}$ obtained by the single breath and by the steady state methods plotted in relation to the lung volume at which the measurements were made. The lung volume for the steady state measurements is taken as the F.R.C. The steady state values fall approximately on the line relating the single breath values with lung volume; thus, the dependence of $D_{L}$ on lung volume can explain the whole of the difference between the values obtained for the $D_{L}$ of normal subjects by the single breath and steady state methods.
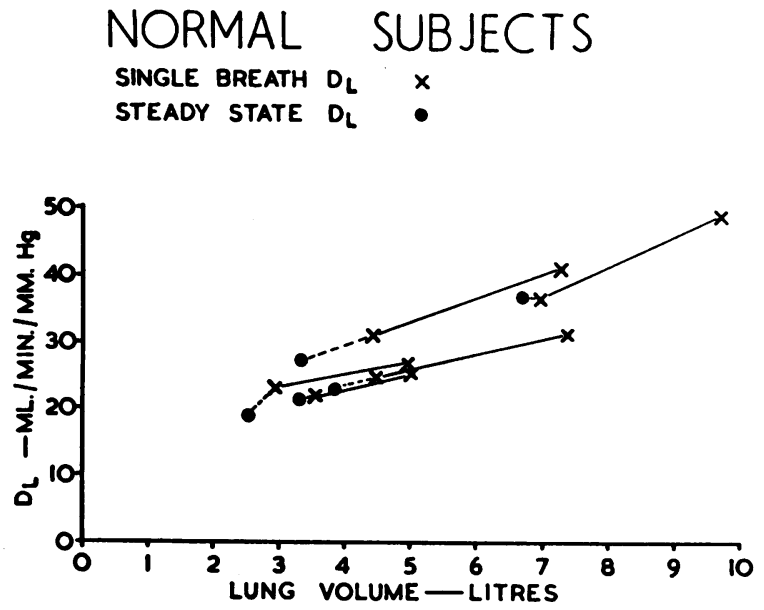

Fig. 8. The Relationship Between $D_{\text {L, Meas- }}$ URed by the Single Breath and Steady State (End Tidal) Methods, and the Lung Volume at Which the Measurements Were Made (Normal Subjects) 


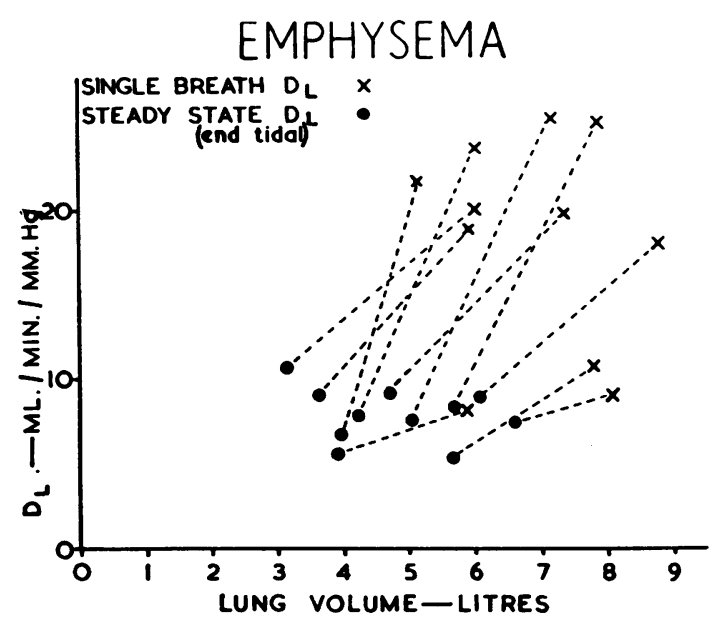

Fig. 9. The Relationship Between $D_{\mathrm{L}}$, Measured by the Single Breath and Steady State (End Tidal) Methods, and the Lung Volume at Which the Measurements Were Made (Patients with EmphySEMA)

Other factors, in addition to those discussed above, may account for the different results obtained by the single breath and steady state methods in patients with emphysema. Failure of the alveolar $\mathrm{CO}$ concentration to reach a plateau in the expired air in patients with emphysema means that the end tidal sample has no definite value and will vary considerably with the volume expired (Figure 6). The end tidal sample bears no relationship to the mean alveolar concentration of $\mathrm{CO}$ which is lower than that of the lowest $\mathrm{CO}$ concentration expired during a full expiration. Since the end tidal sample is higher than the mean alveolar CO the value obtained for $D_{L}$ is lower than the single breath $D_{L}$. Figure 9 shows the relationship between the single breath and steady state $D_{L}$, the latter being calculated from the end tidal samples. Some patients with emphysema have a normal $D_{L}$ by the single breath method but the results are uniformly low by the steady state method. These low values are due, in most cases, to the high end tidal samples and cannot be explained solely by the difference in lung volumes at which the two tests are made.

The steady state $D_{L}$ calculated from the mean alveolar $\mathrm{CO}$, derived by using a modification of Filley's method, gives values close to those of the single breath $D_{L}$ (Table VI). The values of $D_{L}$ obtained by the modification of Filley's steady state method are slightly lower than the single breath $D_{L}$ in four of the five subjects but the lower value may be due, as in the normal subjects, to the smaller lung volume at which the measurements were made (Figure 10). The agreement between these methods is particularly close when one considers that Filley's method of calculation of the mean alveolar CO is least accurate when used in subjects at rest, in whom the dead space may constitute a large proportion of the tidal volume. This modification of Filley's method allows calculation of the mean end capillary $\mathrm{CO}$ instead of the arterial $\mathrm{CO}$ which is measured in Filley's original method. The mean alveolar $\mathrm{CO}$ calculated is thus uninfluenced by venous shunts and this should bring the measurement of $D_{L}$ into line with that of $\mathrm{D}_{\mathrm{O}_{2}}$ by the method of Riley, Cournand, and Donald (19).

Physiological implications of the results of fractional measurement of $D_{L}$

Previous investigations $(8,20,21)$ have shown that in normal subjects the ventilation-perfusion ratio is uniform in fractional samples obtained during a full expiration. Since the ventilation is uniform in normal subjects it is not surprising to find that $D_{L}$ calculated from the fractional samples is also uniform.

In patients with emphysema, the $D_{L}$ per unit of lung volume from which the expired air originates

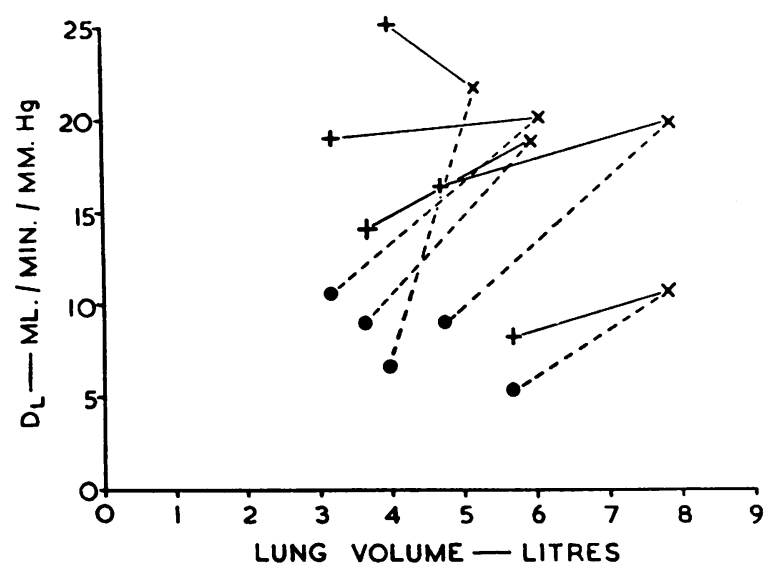

Fig. 10. The Relationship Between $D_{L}$, Measured by the Single Breath and the Two Steady State Methods, and the Lung Volume at Which the Measurements Were Made

$\times$, single breath $\mathrm{D}_{\mathrm{L}} ; \boldsymbol{\bullet}$, steady state $\mathrm{D}_{\mathrm{L}}$ (end tidal); + , steady state $D_{L}$ (modification of Filley's method). 
is uniform for the different fractions of the expired air. The units of lung volume from which the expired air arises are not necessarily anatomical regions of the lungs, but it is known that the air expired first comes from parts of the lung in which the ventilation-perfusion ratio is high and the air expired last comes from parts of the lung with a low ventilation-perfusion ratio $(8,20)$. The relationship between $\mathrm{D}_{\mathrm{L}}$, the diffusing capacity of the pulmonary membrane $D_{M}$, the reaction rate of $\mathrm{CO}$ with hemoglobin $\theta$, and the capillary blood volume $V_{c}$ is given by the equation:

$$
\frac{1}{\mathrm{D}_{\mathrm{L}}}=\frac{1}{\mathrm{D}_{\mathrm{M}}}+\frac{1}{\theta \mathrm{V}_{\mathrm{c}}} .
$$

A uniform $D_{L}$ suggests that both $D_{M}$ and $V_{c}$ remain uniform in the various regions of the lung. Reduction of $D_{\mathbf{M}}$ in emphysema, when it occurs, most probably is due to a reduction in surface area of the lung and it is unlikely that such a reduction would be accompanied by the increase in $\mathrm{V}_{\mathrm{c}}$ which would be necessary to maintain $\mathrm{D}_{\mathrm{L}}$ constant. $V_{c}$ is not necessarily directly related to the perfusion of the lung, but if it were, since $V_{c}$ per unit lung volume remains uniform throughout the lung one would expect that the variation in the ventilation-perfusion ratio would be the same as the variation in ventilation. This hypothesis is supported by the results shown in Table VII; the ratio of the ventilation in the fractional samples is approximately the same as that of the ventilationperfusion ratios.

Histological examination of the lungs in emphysema shows regions in which breakdown of the alveolar walls has occurred and this might be used as evidence against a uniform perfusion of all parts of the lung. It is quite possible that the parts of the lung with the greatest alveolar damage are the parts of the lung containing trapped gas (22) which would not take part in gas diffusion.

\section{Clinical value of the single breath and steady state $D_{L}$}

1. The single breath $D_{L}$. This measurement is independent of unevenness of ventilation and is affected only by the diffusing capacity of the pulmonary membrane and by the capillary blood volume of the lungs. It is a measure of the potential diffusing capacity of the lungs since the diffusing capacity of parts of the lung which receive very little ventilation has the same effect on the final result as the diffusing capacity of well-ventilated parts of the lung. The single breath $D_{L}$, therefore, provides a useful measure of diffusion in diseases such as the pulmonary infiltrations where the diffusing capacity of the membrane is impaired; but in diseases with unequal ventilation the diffusing capacity measured may have no relationship to the ability of the lungs to take up oxygen.

2. The steady state $D_{L}$ measured by the use of end tidal samples. In normal subjects or in patients with uniform ventilation of the lungs this test will give the same result as the single breath test when allowance is made for the different lung volumes at which the measurements are made. This test is more time consuming to carry out than the single breath test and has no advantages over the latter test for measurements made at rest. It has the advantage that measurements can be made during exercise and the ability of the subject to increase $D_{L}$ on exercise may be of clinical importance. When used in patients one must bear in mind that if the ventilation becomes uneven on exercise the measure of $D_{L}$ by this method will be inaccurate. This test has proved to be of some value clinically and in emphysema it provides a measure which is useful for assessing disability and prognosis (23). The reason for the usefulness of this test is that it measures the combined effect of poor diffusion and unequal ventilation. It is not a measure of diffusion alone when the ventilation is uneven and when applied to patients with uneven ventilation the results should not be expressed as $\mathrm{ml}$. CO per minute per $\mathrm{mm}$. $\mathrm{Hg}$.

3. The steady state $D_{L}$ (Filley's method). This method, modified by the measurement of mixed venous $\mathrm{pCO}_{2}$ instead of arterial $\mathrm{pCO}_{2}$, provides a bloodless method for measuring $D_{L}$ at rest. With this modification the result is unaffected by venous shunts. The modified method has not been tested during exercise, but it is probably unsuited for use under conditions in which the cardiac output is not even approximately known and in which the circulation time is more rapid. The original method of Filley still provides the only method of measurement of $D_{L}$ on exercise in patients with unequal distribution of the inspired air. 


\section{SUM MARY}

The diffusing capacity of the lungs for $\mathrm{CO}$ $\left(D_{\mathrm{L}}\right)$ has been measured in 5 normal subjects and in 11 patients with emphysema by the single breath method and by the steady state method, using end tidal samples as a measure of the mean alveolar $\mathrm{CO}$ tension. In five of the patients with emphysema, $D_{L}$ was also calculated by a modification of Filley's method.

Fractional samples were taken from a full expiration after breath holding and $D_{\mathbf{L}}$ was calculated for each sample by the single breath method. In normal subjects and in patients with emphysema, $D_{\mathbf{L}}$ was uniform throughout the expired air. Fractional analysis of the expired air of normal subjects in the steady state breathing $\mathrm{CO}$ showed that the concentration of $\mathrm{CO}$ in the lungs was uniform. In these subjects end tidal samples approximated the mean alveolar concentration of $\mathrm{CO}$ and could be used in the calculation of the steady state $D_{L}$. Measurement of $D_{L}$ by the single breath and steady state methods gave the same results in normal subjects when allowance was made for the different lung volumes at which the measurements were made.

Patients with emphysema did not have uniform concentrations of $\mathrm{CO}$ throughout the lung in the steady state; end tidal samples bore no relationship to the mean alveolar $\mathrm{CO}$ and could not be used for calculation of $\mathrm{D}_{\mathrm{L}}$.

A bloodless modification of Filley's method of calculation of the steady state $D_{\mathbf{L}}$ is described. This method gave results which were close to those of the single breath $D_{L}$ measured in the same subjects.

The clinical value of the single breath and steady state methods for measurement of $D_{L}$ is discussed.

\section{ACKNOWLEDGMENTS}

I am grateful to Miss J. A. West and Miss M. Endacott for skilled technical assistance.

\section{APPENDIX}

Correction, for time of expiration, of $C O$ samples expired at the end of a period of steady state breathing

Example: Subject, M.E.; correction of the 0.5 liter sample. $D_{L}$ at F.R.C. equals $21 \mathrm{ml}$. CO per minute per $\mathrm{mm}$. Hg. Barometric pressure equals $763 \mathrm{~mm}$. Hg. Approximate alveolar volume equals 3.0 liters. Delay of expiration of 0.5 liter sample after end of normal expira- tion (measured from tracing) equals 0.61 second. Measured concentration of $\mathrm{CO}$ in 0.5 liter sample $\left(\mathrm{F}_{\mathrm{E} 0 \mathrm{O}}\right)$ equals 0.1628 per cent. From the $D_{L}$ equation (5):

$$
21=\frac{\ln . \frac{F_{I_{c o}}}{F_{E_{c o}}} \times 3000 \times 60}{0.61 \times 716} .
$$

ln. $\frac{F_{I_{\mathrm{co}}}}{\mathrm{F}_{\mathrm{E}_{\mathrm{co}}}}$ equals 0.0510 . Therefore, $\mathrm{F}_{\mathrm{IN}_{\mathrm{eO}}}$ equals 1.052 times

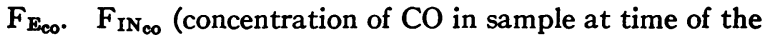
end of a normal expiration) equals 1.052 times 0.1628 equals 0.1714 per cent.

\section{REFERENCES}

1. Filley, G. F., MacIntosh, D. J., and Wright, G. W. Carbon monoxide uptake and pulmonary diffusing capacity in normal subjects at rest and during exercise. J. clin. Invest. 1954, 33, 530.

2. Bates, D. V., Boucot, N. G., and Dormer, A. E. The pulmonary diffusing capacity in normal subjects. J. Physiol. 1955, 129, 237.

3. Bates, D. V., and Pearce, J. F. The pulmonary diffusing capacity; a comparison of methods of measurement and a study of the effect of body position. J. Physiol. 1956, 132, 232.

4. Krogh, A., and Krogh, M. On the rate of diffusion of carbonic oxide into the lungs of man. Skand. Arch. Physiol. 1910, 23, 236.

5. Ogilvie, C. M., Forster, R. E., Blakemore, W. S., and Morton, J. W. A standardized breath holding technique for the clinical measurement of the diffusing capacity of the lung for carbon monoxide. J. clin. Invest. 1957, 36, 1.

6. Marks, A., Cugell, D. W., Cadigan, J. B., and Gaensler, E. A. Clinical determination of the diffusion capacity of the lungs. Comparison of methods in normal subjects and patients with "alveolar-capillary block" syndrome. Amer. J. Med. 1957, 22, 51.

7. Linderholm, $\mathrm{H}$. On the significance of $\mathrm{CO}$ tension in pulmonary capillary blood for determination of pulmonary diffusing capacity with the steady state CO method. Acta med. scand. 1957, 156, 413.

8. Marshall, R., Bates, D. V., and Christie, R. V. Fractional analysis of the alveolar air in emphysema. Clin. Sci. 1952, 11, 297.

9. Sivertson, S. E., and Fowler, W. S. Expired alveolar carbon dioxide tension in health and in pulmonary emphysema. J. Lab. clin. Med. 1956, 47, 869.

10. Dill, D. B., Edwards, H. T., and Consolazio, W. V. Blood as a physico-chemical system. XI. Man at rest. J. biol. Chem. 1937, 118, 635.

11. Bates, D. V., and Christie, R. V. Intrapulmonary mixing of helium in health and in emphysema. Clin. Sci. 1950, 9, 17.

12. Forster, R. E., Roughton, F. J. W., Cander, L., Briscoe, W. A., and Kreuzer, F. Relationship between diffusing capacity of pulmonary membrane and 
pulmonary capillary blood volume in man. Amer. J. Physiol. 1955, 183, 615.

13. Rahn, H., and Fenn, W. O. A Graphical Analysis of the Respiratory Gas Exchange; The $\mathrm{O}_{2}-\mathrm{CO}_{2}$ Diagram. Washington, The American Physiological Society, 1955.

14. Forster, R. E., Fowler, W. S., and Bates, D. V. Considerations on the uptake of carbon monoxide by the lungs. J. clin. Invest. 1954, 33, 1128.

15. Gréhant, N. Recherches physiques sur la respiration de l'homme. J. Anat. (Paris) 1864, 1, 532.

16. Dubois, A. B., Britt, A. G., and Fenn, W. O. Alveolar $\mathrm{CO}_{2}$ during the respiratory cycle. J. appl. Physiol. 1952, 4, 535.

17. Forster, R. E., Fowler, W. S., Bates, D. V., and Van Lingen, B. The absorption of carbon monoxide by the lungs during breathholding. $\mathrm{J}$. clin. Invest. 1954, 33, 1135.

18. Krogh, M. The diffusion of gases through the lungs of man. J. Physiol. 1915, 49, 271.
19. Riley, R. L., Cournand, A., and Donald, K. W. Analysis of factors affecting partial pressures of oxygen and carbon dioxide in gas and blood of lungs: Methods. J. appl. Physiol. 1951, 4, 102.

20. Roelsen, E. The composition of the alveolar air investigated by fractional sampling: Comparative investigations on normal persons and patients with bronchial asthma and pulmonary emphysema. Acta med. scand. 1939, 98, 141.

21. Cotton, F. S. Studies in respiration; I. A simple method for the investigation of fractional samples of expired air. Austr. J. exp. Biol. med. Sci. 1939, $17,425$.

22. Bedell, G. N., Marshall, R., DuBois, A. B., and Comroe, J. H., Jr. Plethysmographic determination of the volume of gas trapped in the lungs. J. clin. Invest. 1956, 35, 664 .

23. Bates, D. V., Knott, J. M. S., and Christie, R. V. Respiratory function in emphysema in relation to prognosis. Quart. J. Med. 1956, 25, 137. 